Abstracta Iranica Abstracta Iranica

Revue bibliographique pour le domaine irano-aryen

Volume 32-33 | 2013

Comptes rendus des publications de 2009-2010

Denis Hermann. La défense de l'enseignement de l'arabe au cours du mouvement constitutionnel iranien (1906-1911)

Asyeh Ghafourian

CpenEdition

Journals

Édition électronique

URL : http://journals.openedition.org/abstractairanica/40772

DOI : 10.4000/abstractairanica.40772

ISSN : 1961-960X

Éditeur :

CNRS (UMR 7528 Mondes iraniens et indiens), Éditions de l'IFRI

Édition imprimée

Date de publication : 1 décembre 2013

ISSN : 0240-8910

Référence électronique

Asyeh Ghafourian, «Denis Hermann. La défense de l'enseignement de l'arabe au cours du mouvement constitutionnel iranien (1906-1911)», Abstracta Iranica [En ligne], Volume 32-33 | 2013, document 290, mis en ligne le 01 juillet 2016, consulté le 26 septembre 2020. URL : http://journals.openedition.org/ abstractairanica/40772 ; DOI : https://doi.org/10.4000/abstractairanica.40772

Ce document a été généré automatiquement le 26 septembre 2020.

Tous droits réservés 


\title{
Denis Hermann. La défense de l'enseignement de l'arabe au cours du mouvement constitutionnel iranien (1906-1911)
}

\author{
Asyeh Ghafourian
}

\section{RÉFÉRENCE}

Denis Hermann. « La défense de l'enseignement de l'arabe au cours du mouvement constitutionnel iranien (1906-1911) », in : Fabrizio Speziale, Denis Hermann, eds., Muslim Cultures in the Indo-Iranian World during the Early-Modern and Modern Periods. Berlin - Tehran, Klaus Schwarz Verlag - Institut français de recherche en Iran, 2010, p. 301- 321. (Islamkundlische Untersuchungen, Band 290 - Bibliothèque iranienne, vol. 69.)

1 L'enseignement en Iran à la première moitié du $\mathrm{XX}^{\mathrm{e}} \mathrm{s}$. n'est pas un sujet régulièrement traité. Mais, ici l'A. s'intéresse en particulier à l'enseignement de la langue arabe pendant le mouvement constitutionnel.

2 Certaines personnalités intellectuelles de l'époque qui sont par ailleurs constitutionnalistes, bataillent pour imposer des réformes au sein de l'enseignement. Le départ des étudiants vers l'Europe et leur retour, alimente l'idée de la nécessité de moderniser l'enseignement en Iran. Cependant la modernisation de l'enseignement qui écarterait, entre autre, l'enseignement de l'arabe, trouve ses adversaires dans les rangs des ŠeyHī. Ces derniers considèrent que la langue arabe est nécessaire à l'étude du Coran et des hadịts. De même, le fait d'encourager l'enseignement de l'arabe par le Sheykhisme était considéré comme une barrière au soufisme, qui prônait l'étude du persan. 
3 Par ailleurs, les partisans de l'enseignement du persan l'estimaient comme élément de cohésion nationale et de renforcement de la culture iranienne. Parallèlement, les clercs n'étaient pas unanimes au sujet de l'enseignement de l'arabe. Deux courants se dessinent ainsi : l'un pour l'enseignement de l'arabe et l'autre pour le persan. Il nous est permis de penser que le courant insistant sur le maintien et même le renforcement de l'arabe, craint que dans le cas contraire l'islam et sa diffusion soient menacés.

\section{AUTEURS}

\section{ASYEH GHAFOURIAN}

Bulac, Paris 